\title{
Study of the Indicators of Climate Change in Mysore District, Karnataka, India
}

\author{
Alaa Samy Hafez Megahed ${ }^{1,2}$, S. Srikantaswamy ${ }^{{ }^{*}}$ \\ ${ }^{1}$ Dept. of Studies in Environmental Science, University of Mysore, Manasagangothri, Mysore, Karnataka, India \\ ${ }^{2}$ Social Studies Department, Socio-economic Studies Division, Desert Research Center, Matariya, Cairo, Egypt \\ Email: *srikantas@hotmail.com
}

How to cite this paper: Megahed, A.S.H and Srikantaswamy, S. (2020) Study of the Indicators of Climate Change in Mysore District, Karnataka, India. Atmospheric and Climate Sciences, 10, 159-167. https://doi.org/10.4236/acs.2020.102008

Received: February 7, 2020

Accepted: April 11, 2020

Published: April 14, 2020

Copyright ( 2020 by author(s) and Scientific Research Publishing Inc. This work is licensed under the Creative Commons Attribution International License (CC BY 4.0). http://creativecommons.org/licenses/by/4.0/ cc (i) Open Access

\begin{abstract}
The study aims to find out the changes of climate change parameters for Mysore district. To analyse the variations in climatic parameters like Rainfall and Temperature, data were used for a period of 1986-2016, and Humidity data were used for a period of 2000-2016 to study the nature of climate change in the region. The findings of the study show that the climate variability and climate change for Mysore district, the monthly Rainfall is increased and monsoon Rainfall shows a decrease in trend. And the monthly, summer, monsoon minimum Temperature shows that decrease. Generally, the monthly maximum Temperature has decreased, but in case of summer and monsoon seasons increased respectively, and the monthly Relative Humidity has increased (positive). There is a decrease in Relative Humidity from January to April, and increase in the Relative Humidity during Monsoon season for Mysore District. The Annual average of Relative Humidity shows that it is increased for Mysore District.
\end{abstract}

\section{Keywords}

Climate Change, Rainfall, Temperature, Mysore District

\section{Introduction}

Weather and climate are key determinants of life on Earth, as they are essential for health, food production and well-being [1]. Accordingly, any disturbance in weather and climatic conditions would in turn affect the natural ecosystems and the wellbeing of the living organisms all over the globe [2]. Within this context, the Inter-governmental Panel on Climate Change [3] refers to climate as "the average weather in terms of the mean and its variability over a certain time-span and a certain area". Climate varies from place to place, depending on several 
geographical factors such as latitude, distance to the sea, vegetation cover, presence or absence of mountains, etc. Climate also varies from time to time; from season to season, year to year, decade to decade or on much longer time-scales, such as the Ice Ages [4]. Climate change refers to a change of climate (general weather conditions prevailing in an area over a long period) which is attributed directly or indirectly to human activity that alters the composition of the global atmosphere and which is in addition to natural climate variability observed over comparable time periods [5]. Climate change refers to all forms of climatic inconstancy, regardless of their statistical nature or physical causes [6]. Climate change refers to a statistically significant variation in either the mean state of the climate or in its variability, persisting for an extended period (typically decades or longer) [7]. Climate change may be due to natural processes or external forcing, or to persistent anthropogenic changes in the composition of the atmosphere or in land-use [8]. Climate change refers to a statistically significant variation in either the mean state of the climate or in its variability, persisting for an extended period. It may be due to natural processes or external forcing or to persistent anthropogenic changes in the composition of the atmosphere or in land-use [9]. Climate Change refers to the climate of a place or region is changed if over an extended period (typically decades or longer) there is a statistically significant change in measurements of either the mean state or variability of the climate for that place or region [10]. The climate change as a change in the state of the climate can be identified by changes in the mean and/or the variability of its properties, and persists for an extended period, typically decades or longer. Climate change may be due to natural internal processes or external forcing, or to persistent anthropogenic changes in the composition of the atmosphere or in land use [11]. Though, the greenhouse gas itself is present in the atmosphere which makes the earth suitable for existence, as it absorbs and emits radiation within the thermal infrared range, warming up the earth's atmosphere. The primary greenhouse gases in the Earth's atmosphere are water vapor, carbon dioxide, methane, nitrous oxide, and ozone. However, the human activities increased the amounts of GHGs already present and lead to the production of other GHGs. There are 6 major anthropogenic greenhouse gases that cause global warming and hence climate change. These are: Carbon dioxide $\mathrm{CO}_{2}, \mathrm{Me}-$ thane $\mathrm{CH}_{4}$, Nitrous Oxide $\mathrm{N}_{2} \mathrm{O}$, Hydrofluorocarbons HFCs, Perfluorocarbons PFCs and Sulphur hexafluoride $\mathrm{SF}_{6}$ [12]. This study attempts to investigate into the trend analysis of climate variables of Mysore district based on centurial data. This would aid in the better understanding of the emerging climatic situation in the study area.

\section{Methodology}

The climatic conditions of the region were analysed using secondary data based on various indicators which constitutes weather conditions in the region. The annual averages of the following indicators were used for a period of 1986-2016 
for the districts to study the nature of climate change in the region. The climatic condition of the region depends on the various indicators which constitutes weather conditions in the region. The following indicators have been considered for this study. Regression analysis has been used to study the pattern, direction and nature of changes in these indicators of climatic conditions. Final equation used in the study is:

$$
Y=a+b T+c T^{2}
$$

where,

$Y:$ is the climate variable whose variation over time is being analysed;

$T:$ is the time-period of the study in terms of number of years;

$T^{2}$ : is the Square of the time period in terms of number of years.

\section{Results and Discussion}

\subsection{Variability in Temperature}

The monthly, summer, monsoon minimum Temperature have decreased (Figures 1-3) and monthly maximum Temperature data shows that there is decreasing (negative) (Figure 4 and Figure 5); the monsoon and summer maximum

Minimum monthly Temperature

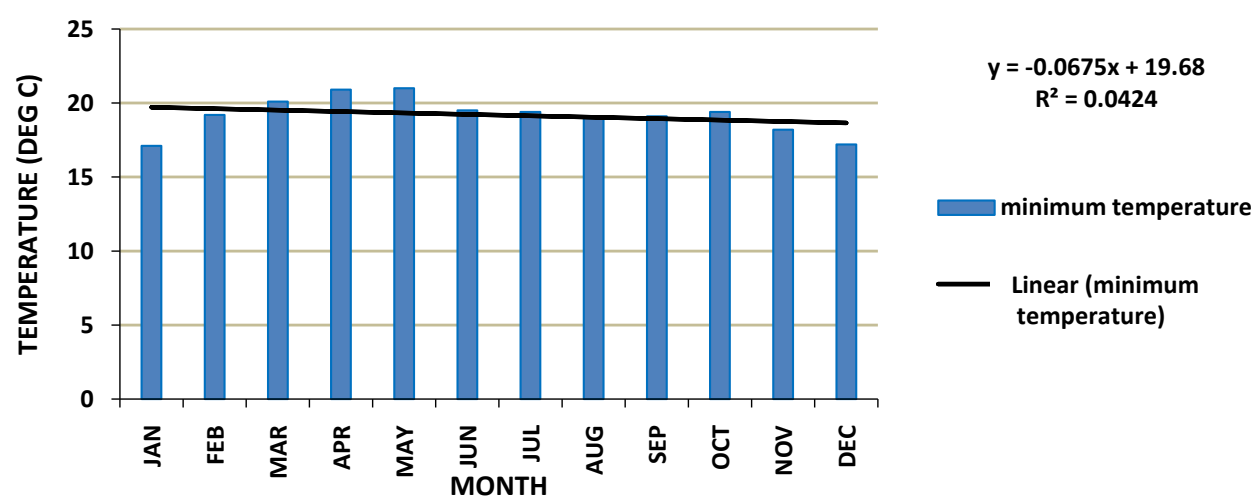

Figure 1. Monthly average minimum temperature trend for Mysore district from 1986-2016.

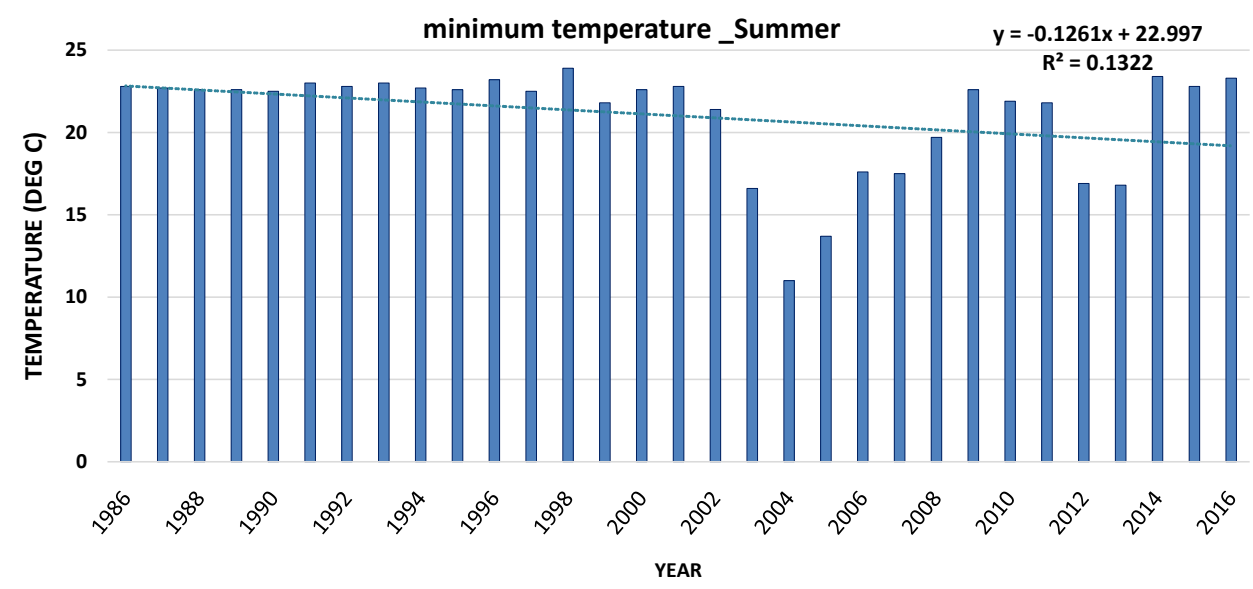

Figure 2. Summer average minimum temperature trend for Mysore district from 1986-2016. 


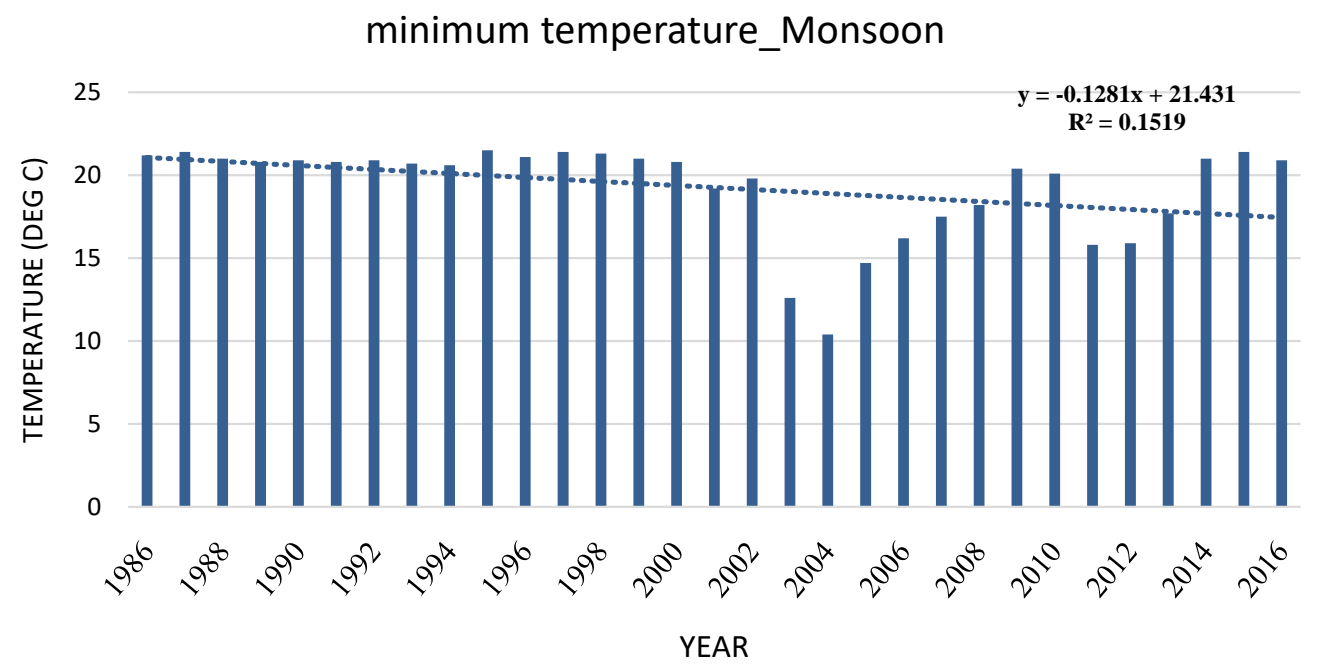

Figure 3. Monsoon average minimum temperature trend for Mysore district from 1986-2016.

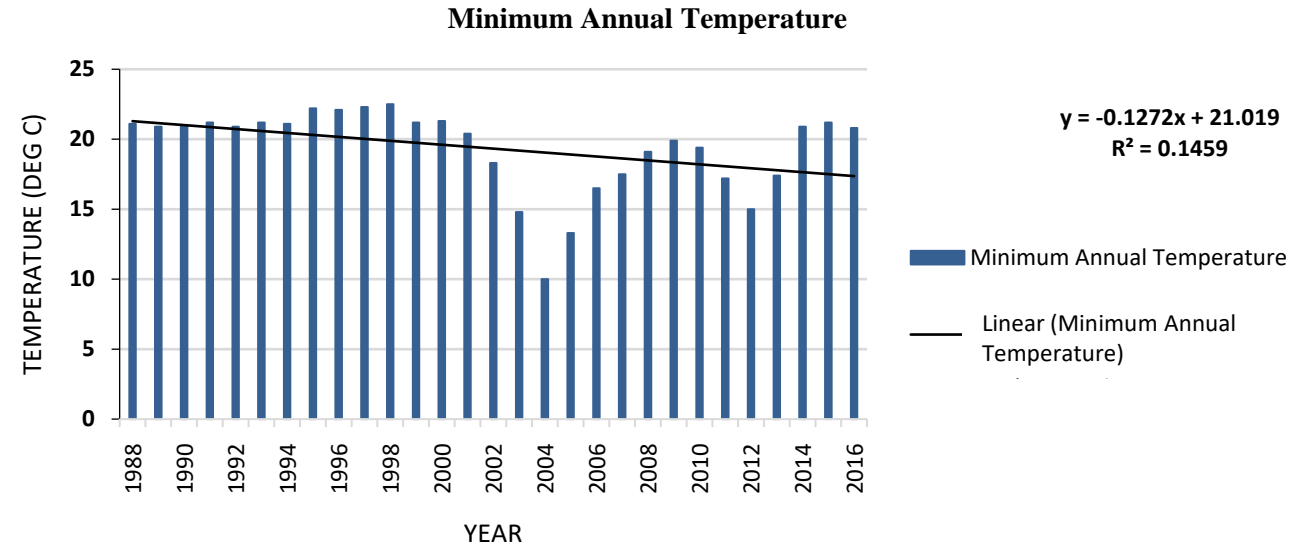

Figure 4. Annual average minimum temperature trend for Mysore district from 1986-2016.

\section{Maximum Monthly Temperature}

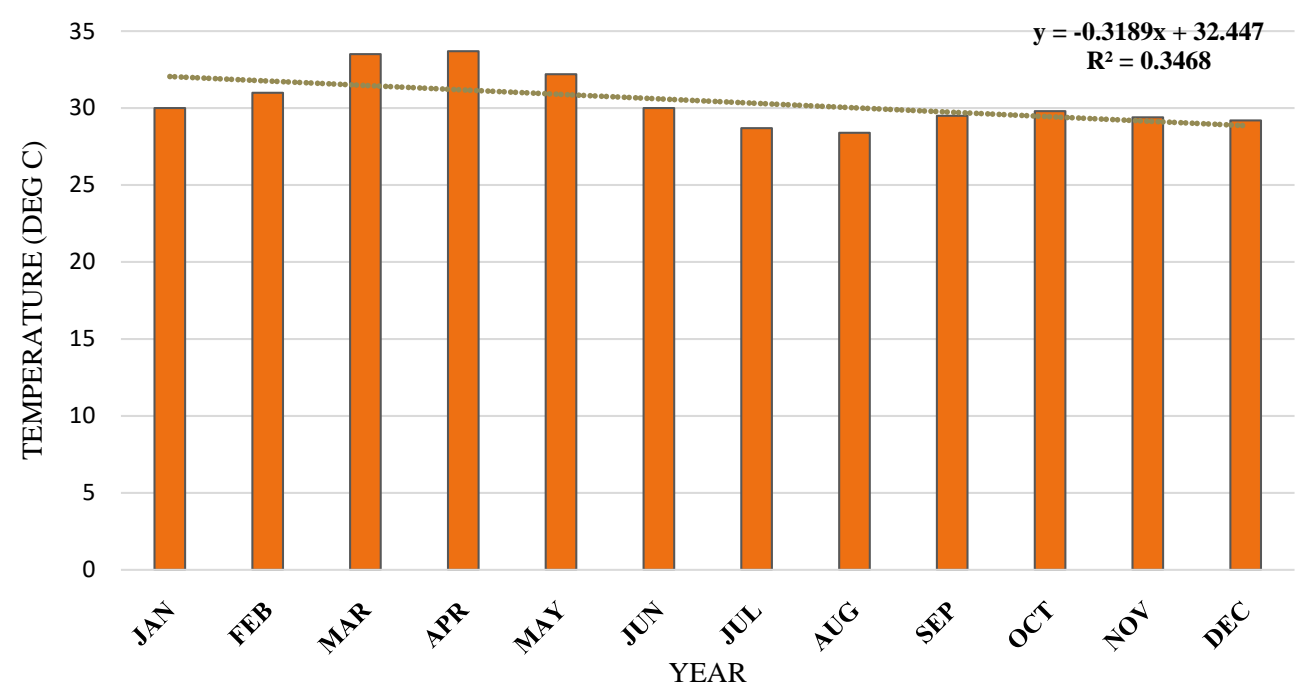

Figure 5. Monthly average maximum temperature trend for Mysore district from 1986-2016. 
Temperature data shows that there is increasing (positive) (Figure 5 and Figure 6) for study area. The Annual average minimum Temperature shows that decrease in the trend (Figure 7), in case of Annual Maximum Temperature shows that increase in trend (Figure 8) for Mysore District.

\subsection{Variability in Rainfall}

Variability in the Rainfall and Temperature data are studied for the study area. The monthly Rainfall data shows increasing in the trend and monsoon Rainfall shows that a decreasing in the trend (Figure 9 and Figure 10) for the study area. The Annual average Rainfall data shows that it is decreased (Figure 11) for Mysore District.

\section{Relative Humidity (RH)}

The Relative Humidity is a ratio of the actual amount of water vapour in the atmospheric compared to the saturation amount of water vapor. If the Relative Humidity percentage increases then the air water mixture is more humid. The

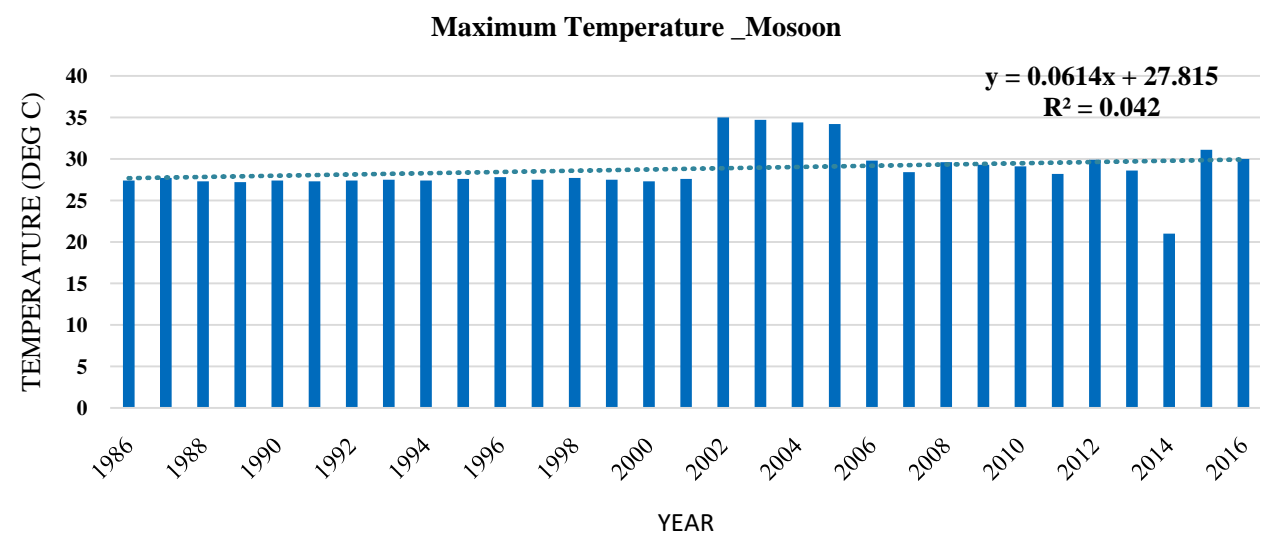

Figure 6. Monsoon average maximum temperature trend for Mysore district from 1986-2016.

Maximum Temperture_Summer

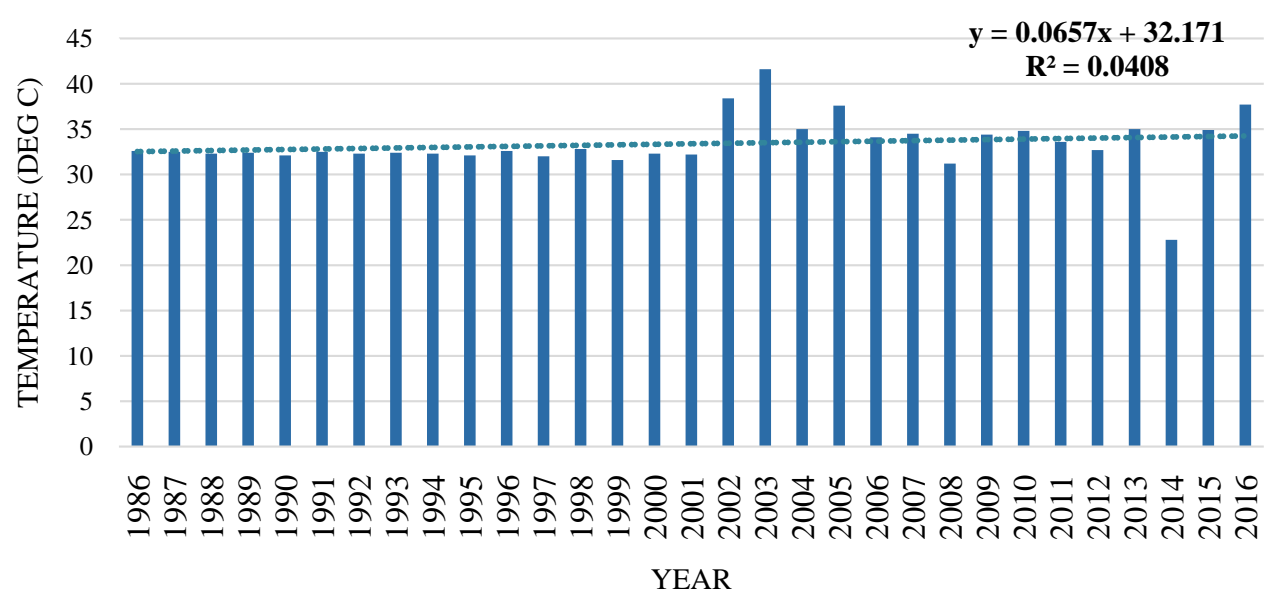

Figure 7. Summer average maximum temperature trend for Mysore district from 1986-2016. 


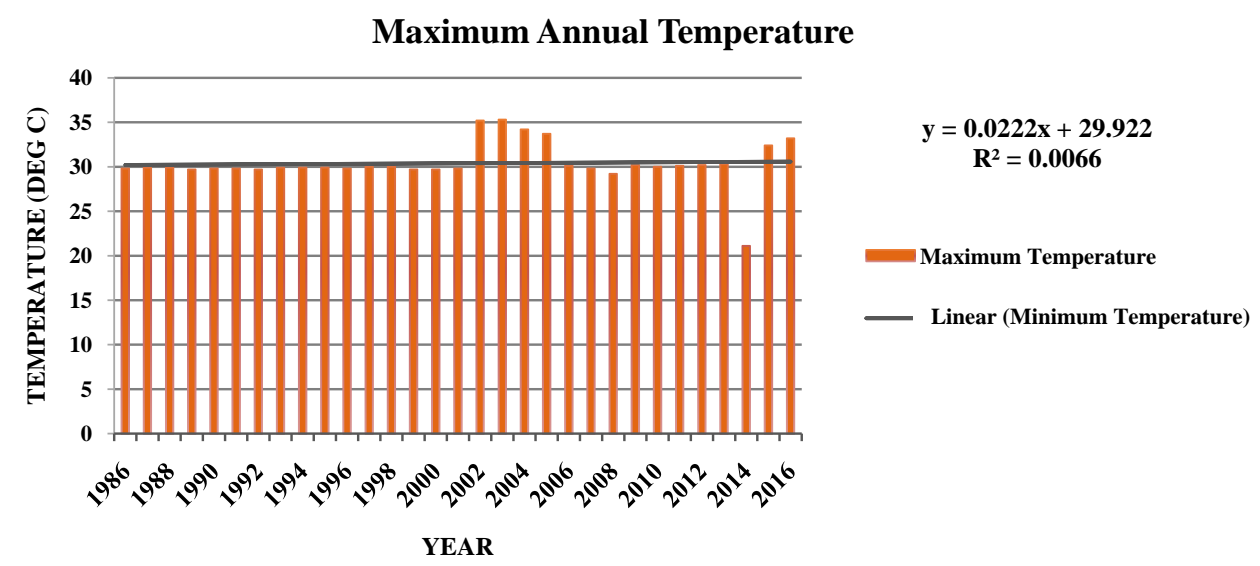

Figure 8. Annual average maximum Temperature trend for Mysore District from 1986-2016.

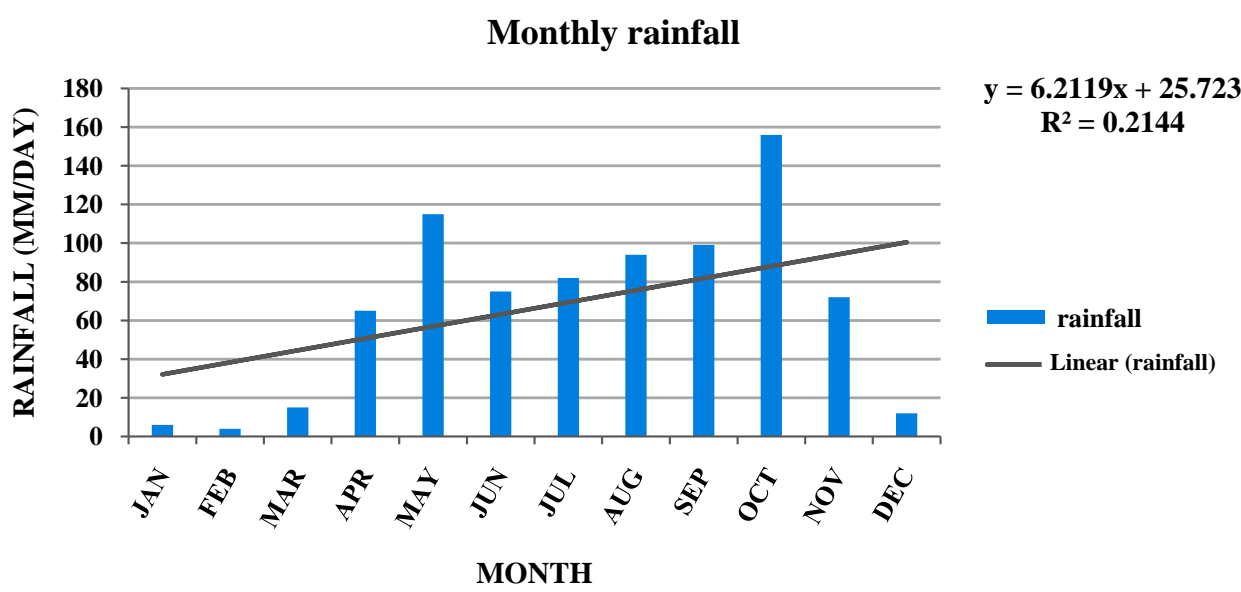

Figure 9. Monthly average Rainfall trend for Mysore District from 1986-2016.

\section{Monsoon Rainfall}

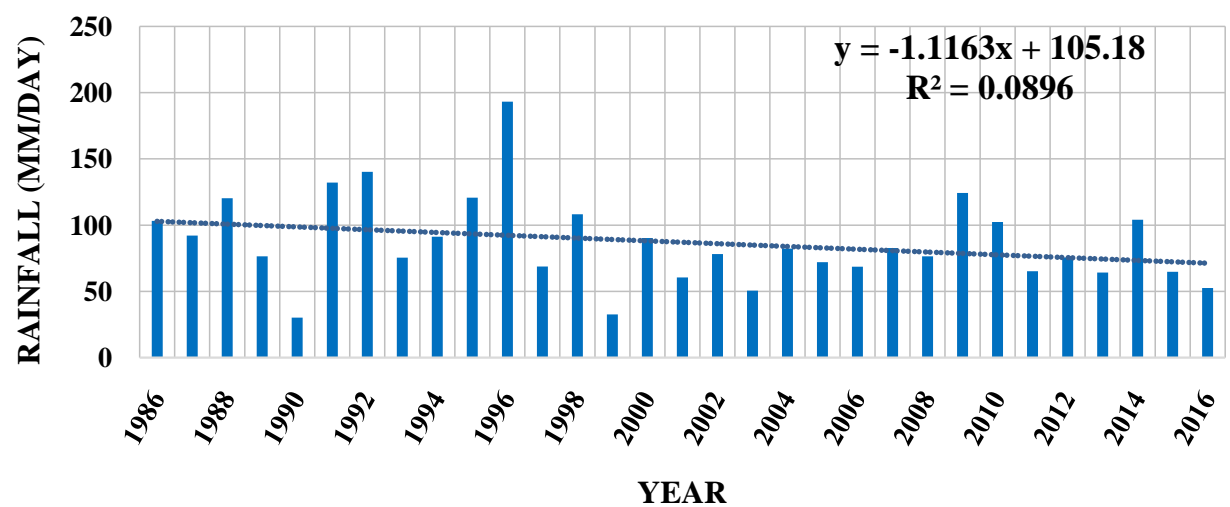

Figure 10. Monsoon average Rainfall trend for Mysore District from 1986-2016.

monthly relative humidity shows that increase (positive) in trend. There is a decrease in $\mathrm{RH}$ from January to April, and increase in the RH during Monsoon season for Mysore District (Figure 12). The Annual average Relative Humidity shows that increase in trend (Figure 13) for Mysore District. 


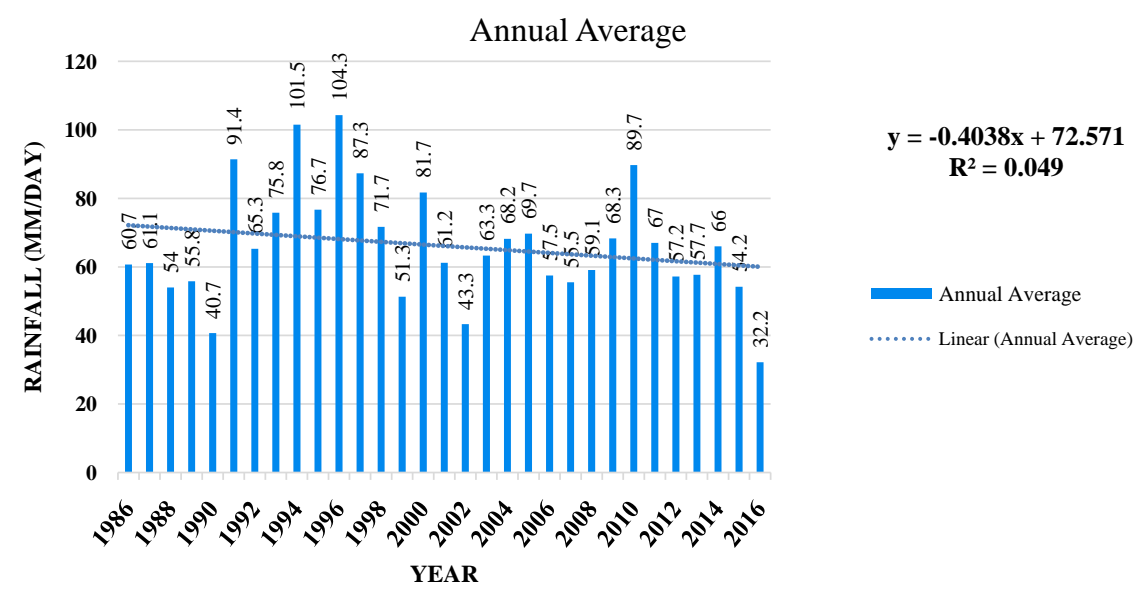

Figure 11. Annual average rainfall trend for Mysore district from 1986-2016.

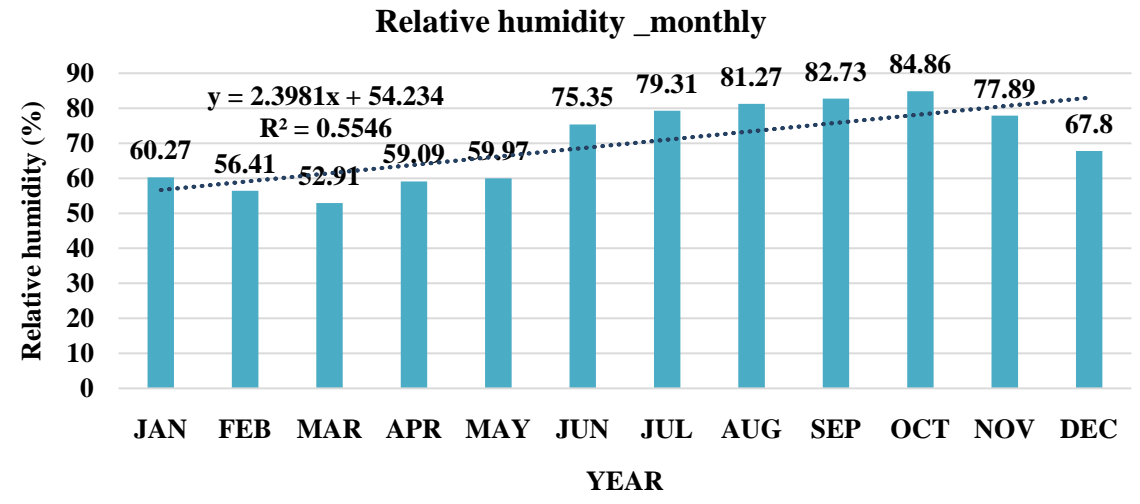

Figure 12. Monthly average relative humidity trend for Mysore district from 2000-2016.

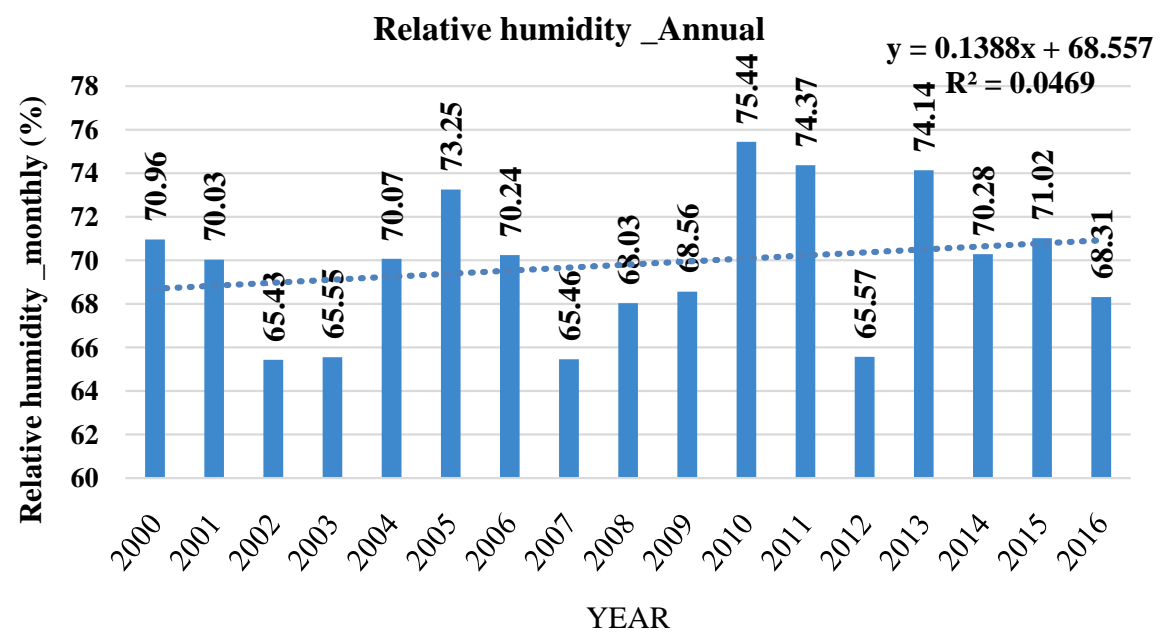

Figure 13. Annual average relative humidity trend for Mysore district from 2000-2016.

\section{Conclusion}

Climate variability is the variations in season to season wise and climate change is due to year to year changes from weather patterns and it is a good example to study climate for the selected area and main thing is that the outcome of the 
"Global Warming" has now started showing its impacts worldwide; climate is one of the important factors of agricultural productivity which directly impact on food production across the globe. Hence, the rainfall and temperature play an important role in the climate change, so when Temperature increases and the Rainfall decreases, this leads to less water runoff, and if Temperature decreases the Relative Humidity increases because the Relative Humidity is an important factor in between atmosphere. There will always be natural climate variability at many scales-decadal, yearly and short-term extreme events. This means that over the long-term record, there will be ups and downs with the yearly and 30-year averages, even if climate is getting warmer. We cannot expect every summer to be warmer than the previous one, but we can expect and plan for variability.

\section{Conflicts of Interest}

The authors declare no conflicts of interest regarding the publication of this paper.

\section{References}

[1] Houghton, J.T., et al. (2001) Climate Change 2001: The Scientific Basis. The Press Syndicate of the University of Cambridge, Cambridge.

[2] Parry, M., et al. (2001) Millions at Risk: Defining Critical Climate Change Threats and Targets. Global Environmental Change, 11, 181-183. https://doi.org/10.1016/S0959-3780(01)00011-5

[3] Marshall, E. and Randhir, T. (2008) Effect of Climate Change on Watershed System: A Regional Analysis. Climatic Change, 89, 263-280. https://doi.org/10.1007/s10584-007-9389-2

[4] Parry, M. (2001) Climate Change: Where Should Our Research Priorities Be? Global Environmental Change, 11, 257-260. https://doi.org/10.1016/S0959-3780(01)00012-7

[5] Mall, R., et al. (2006) Impact of Climate Change on Indian Agriculture: A Review. Climatic Change, 78, 445-478. https://doi.org/10.1007/s10584-005-9042-X

[6] Kumar, K.K. and Parikh, J. (2001) Indian Agriculture and Climate Sensitivity. Global Environmental Change, 11, 147-154. https://doi.org/10.1016/S0959-3780(01)00004-8

[7] Katz, R.W. (2010) Statistics of Extremes in Climate Change. Climatic Change, 100, 71-76. https://doi.org/10.1007/s10584-010-9834-5

[8] Hartmann, D.L., et al. (2013) Observations: Atmosphere and Surface. In: Climate Change 2013 the Physical Science Basis. Working Group I Contribution to the Fifth Assessment Report of the Intergovernmental Panel on Climate Change, Cambridge University Press, Cambridge, 159-254.

[9] Pielke, R.A. (2005) Land Use and Climate Change. Science, 310, 1625-1626. https://doi.org/10.1126/science.1120529

[10] Dale, V.H. (1997) The Relationship between Land-Use Change and Climate Change. Ecological Applications, 7, 753-769. https://doi.org/10.1890/1051-0761(1997)007[0753:TRBLUC]2.0.CO;2

[11] Olesen, J.E. and Bindi, M. (2002) Consequences of Climate Change for European 
Agricultural Productivity, Land Use and Policy. European Journal of Agronomy, 16, 239-262. https://doi.org/10.1016/S1161-0301(02)00004-7

[12] Arnell, N.W. (2004) Climate Change and Global Water Resources: SRES Emissions and Socio-Economic Scenarios. Global Environmental Change, 14, 31-52. https://doi.org/10.1016/j.gloenvcha.2003.10.006 